\title{
Оптический детектор спина свободных электронов с пространственным разрешением на основе полупроводниковых гетероструктур
}

\author{
В.А. Голяшов ${ }^{1,2}$, Д.А. Кустов ${ }^{1}$, В.С. Русецкий ${ }^{2,3}$, Т.С. Шамирзаев ${ }^{1,2}$, А.В. Миронов ${ }^{2}$, А.Ю. Демин ${ }^{2}$, \\ В.В. Аксенов ${ }^{2}$, О.Е. Терещенко ${ }^{1,2}$ \\ ${ }^{1}$ ИФП СО РАН, 630090, Новосибирск, пр. ак. Лаврентьева 13 \\ ${ }^{2}$ Новосибирский государственный университет, 630090, Новосибирск, ул. Пирогова 2 \\ 3 ЗАО "ЭКРАН-ФЭП", 630060, Новосибирск, ул. Зеленая горка 1. \\ тел: +7 (991) 506-05-06, эл. nочта: vladimirgolyashov@ gmail.com
}

DOI 10.34077/RCSP2021-47

C развитием метода фотоэлектронной спектроскопии с угловым разрешением (ФЭСУP, ARPES) и появлением систем с необычными электронными свойствами, помимо непосредственного изучения электронной структуры этих объектов, интерес стала представлять и их спиновая структура. Вследствие этого актуальной задачей стало эффективное детектирование спиновой поляризации фотоэмитированных электронов. На данный момент наибольшее распространение получили два типа спин-детекторов - детекторы Мотта и так называемые VLEED детекторы. Обладая сравнимой конечной эффективностью, данные типы детекторов имеют общий недостаток - они сугубо одноканальные, и позволяют измерять только среднюю спиновую поляризацию электронного пучка в целом, что существенно ограничивает их эффективность применительно к методу ARPES.

В данной работе обсуждается возможность создания пространственно-чувствительного спиндетектора на основе гибридной структуры - полупроводниковой гетероструктуры, на поверхность

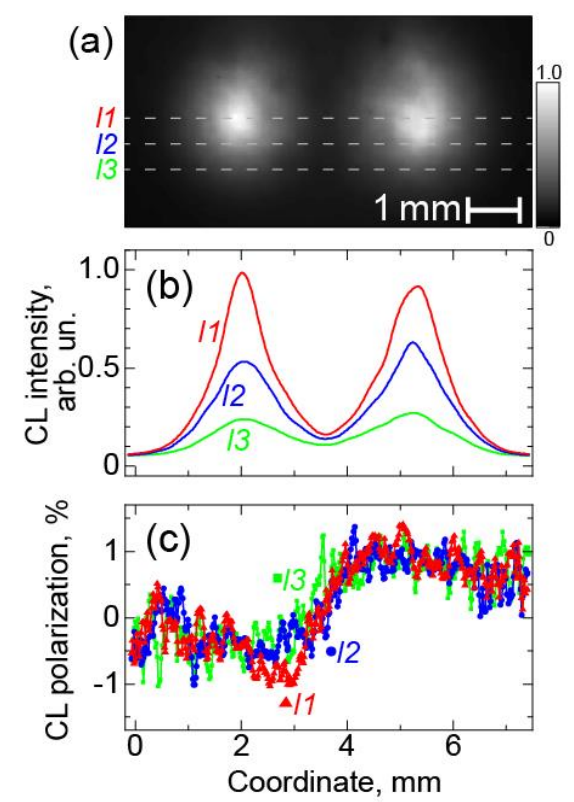

Рис. 1. (а) Изображение КЛ, возникающей при инжекции двух пучков электронов противоположными направлениями поляризации по спину в анодную гетероструктуру с КЯ GaAs в $\mathrm{AlGaAs}$, распределения интенсивности (b) и циркулярной поляризации (c) КЛ вдоль указанных линий $(\mathrm{E}=1$ эВ, T = $300 \mathrm{~K})$. которой осажден тонкий ферромагнитный (ФМ) слой, позволяющей регистрировать пространственное распределение и поляризацию возникающей при инжекции в нее поляризованных по спину электронов катодолюминесценции (КЛ) [1, 2]. Предлагаемый спиндетектор позволяет измерять три компоненты проекции спина: две компоненты спина в плоскости поверхности, используя тонкий ФМ слой в качестве спин-фильтра, и нормальную к его поверхности компоненту, измеряя циркулярную поляризацию КЛ.

Для демонстрации работы такого твердотельного детектора электронов были изготовлены вакуумные диоды, состоящие из близко расположенных фотокатода $p$ $\mathrm{GaAs}(\mathrm{Cs}, \mathrm{O})$ с отрицательным эффективным электронным сродством (источник поляризованных по спину электронов) и анода-мишени на основе гетероструктуры AlGaAs c квантовыми ямами GaAs, также активированной до состояния ОЭС. Была изучена инжекция поляризованных по спину электронов с кинетическими энергиями в диапазоне 0.5-3.0 eV с пространственным разрешением (рис. 1). Определена эффективность созданного прототипа спин-детектора в зависимости от кинетической энергии детектируемых электронов и температуры мишени. Показано, что зависимость степени циркулярной поляризации КЛ от кинетической энергии инжектируемых электронов и её максимальное значение определяются релаксацией спина в “объеме" полупроводниковой гетероструктуры. Обсуждаются возможные пути увеличения эффективности предложенного спин-детектора и её предельная величина.

\section{Лumepamypa}

[1] V.A. Golyashov, et. al. // Ultramicroscopy 2020, 218, 113076.

[2] O. E. Tereshchenko, et. al. // J. Synchrotron Rad. 2021, v. 28, pp. 864-875. 